\title{
The proof of the pudding is in the eating: Is the DEBQ - External Eating Scale a valid measure of external eating?
}

Citation for published version (APA):

Jansen, A., Nederkoorn, C., Roefs, A., Bongers, P., Teugels, T., \& Havermans, R. (2011). The proof of the pudding is in the eating: Is the DEBQ - External Eating Scale a valid measure of external eating? International Journal of Eating Disorders, 44(2), 164-168. https://doi.org/10.1002/eat.20799

Document status and date:

Published: 01/03/2011

DOI:

10.1002/eat.20799

Document Version:

Publisher's PDF, also known as Version of record

Document license:

Taverne

Please check the document version of this publication:

- A submitted manuscript is the version of the article upon submission and before peer-review. There can be important differences between the submitted version and the official published version of record.

People interested in the research are advised to contact the author for the final version of the publication, or visit the DOI to the publisher's website.

- The final author version and the galley proof are versions of the publication after peer review.

- The final published version features the final layout of the paper including the volume, issue and page numbers.

Link to publication

\footnotetext{
General rights rights.

- You may freely distribute the URL identifying the publication in the public portal. please follow below link for the End User Agreement:

www.umlib.nl/taverne-license

Take down policy

If you believe that this document breaches copyright please contact us at:

repository@maastrichtuniversity.nl

providing details and we will investigate your claim.
}

Copyright and moral rights for the publications made accessible in the public portal are retained by the authors and/or other copyright owners and it is a condition of accessing publications that users recognise and abide by the legal requirements associated with these

- Users may download and print one copy of any publication from the public portal for the purpose of private study or research.

- You may not further distribute the material or use it for any profit-making activity or commercial gain

If the publication is distributed under the terms of Article $25 \mathrm{fa}$ of the Dutch Copyright Act, indicated by the "Taverne" license above, 


\section{The Proof of the Pudding is in the Eating: Is the DEBQ - External Eating Scale a Valid Measure of External Eating?}

\author{
Anita Jansen, $\mathrm{PhD}^{1 *}$ \\ Chantal Nederkoorn, PhD ${ }^{1}$ \\ Anne Roefs, PhD $^{1}$ \\ Peggy Bongers ${ }^{2}$ \\ Teresa Teugels ${ }^{2}$ \\ Remco Havermans, PhD $^{1}$
}

\begin{abstract}
Objective: To test the construct validity and discriminative validity of the widely used Dutch Eating Behavior Questionnaire's (DEBQ) External Eating (EE) subscale.
\end{abstract}

Method: After being exposed to food cues or not participants completed a bogus taste test. Subjective cue reactivity during food exposure and actual food intake after food exposure were measured.

Results: EE scores were unrelated to food intake. A robust main effect of food cue exposure was found but contrary to what was predicted, low EE scorers ate more after food cue exposure than without whereas high EE scorers did not. The actual eating behavior of high and low scorers on the other DEBQ subscales emotional and restrained eating - demonstrated that the EE also lacks discriminative validity.

Discussion: The EE showed no predictive validity and no discriminative validity. The usefulness of the distinction of different types of concerned eaters is questioned. () 2010 by Wiley Periodicals, Inc.

Keywords: Dutch Eating Behavior Questionnaire (DEBQ); external eating; emotional eating; restrained eating; food cue exposure; cue reactivity; craving; validity

(Int J Eat Disord 2011; 44:164-168)
Increased appetitive responding to food cues like the smell and taste of highly palatable foods is called cue reactivity, and it was found in several studies that cue reactivity increases the risk of overeating and relapse in eating disorders and obesity. ${ }^{1,2,3,4,5}$ The extent of cue reactive responding is not the same for everybody. Apart from actual physiological needs (e.g., being food deprived) and one's learned expectations ${ }^{2}$ determining the extent of cue reactivity, it is also suggested that typical personality profiles play a role in one's responding to food cues. ${ }^{6,7,8}$ Following Schachter \& Rodin ${ }^{9}$ who argued decades ago that some people are more sensitive to external food cues than others, the 'external eater' was identified by Van Strien. ${ }^{10}$ An external eater is supposed to be extremely cue reactive and easily overeats in response to external food-related cues such as the sight and smell of palatable foods. ${ }^{10}$ The External Eating (EE) sub-

Accepted 25 November 2009

*Correspondence to: Anita Jansen, Maastricht University, FPN, CPS, P.O. Box 616, 6200 MD Maastricht, the Netherlands. E-mail:a.jansen@maastrichtuniversity.nl

${ }^{1}$ Dept. of Clinical Psychological Science, Faculty of Psychology \& Neurosciences, Maastricht University, Maastricht, the Netherlands

${ }^{2}$ Master Student Health \& Social Psychology, Maastricht University

Published online 2 February 2010 in Wiley Online Library (wileyonlinelibrary.com). DOI: 10.1002/eat.20799

() 2010 Wiley Periodicals, Inc. scale, being a part of the Dutch Eating Behavior Questionnaire (DEBQ), ${ }^{10,11}$ intends to measure this type of eater. People scoring high on the EE are considered to be 'external eaters' and they are assumed to show exaggerated appetitive responding to food cues and, as a consequence, overeating. ${ }^{10,11}$ In this way, external eaters are believed to have a bigger chance of getting overweight or obese compared to people scoring low at the external eating scale.

It was suggested that the classification of overeaters as more or less 'cue reactive' should guide treatment choice. ${ }^{12}$ In a published but still untested treatment decision tree ${ }^{12}$ it is stated that specifically the overweight high scorers on the EE subscale need behavior therapy, more explicitly cue exposure with response prevention as described by Jansen. ${ }^{2,13,14}$ It should however be noted that the predictive validity of this self-report EE scale is not yet determined. Are high EE scorers more cue reactive than low EE scorers and do high EE scorers overeat in response to external food cues whereas low scorers do not?

In a recent study, ${ }^{15}$ self-reported EE was found to be significantly associated with self-reported food cravings - defined as intense appetites that reflect an urge to eat - but in this study actual food intake was not measured. The best test of EE's construct validity is to study actual eating behavior after the manipulation of critical variables. In the absence of 
manipulating food cue exposure, and testing food intake of high vs. low external eaters in response to this manipulation, no fair conclusions can be drawn about the predictive validity of the EE scale.

In the present study, the construct validity of the DEBQ-EE subscale is tested. The DEBQ assumes that high EE-scorers overeat in response to external food cues such as the sight and smell of palatable foods. ${ }^{10,11,12}$ It is therefore hypothesized that high EE scorers will eat significantly more after food cue exposure than without, whereas low EE scorers will not show this increased food intake after food cue exposure. Further, significant positive correlations are expected between EE scores, food exposure induced subjective cue reactivity, and food intake after food cue exposure. To test the discriminant validity of the EE subscale the behavior of high and low external eaters is compared with the behavior of high and low scorers on the other DEBQ subscales: the DEBQ emotional eating subscale (EMO) and the DEBQ restraint subscale (R). Although emotional and external overeating often co-occur, they are supposed to refer to independent constructs, and one type of overeating may be manifested independently of the other. ${ }^{10,11,12}$ If the EE shows discriminant predictability, high scorers on the EMO and R subscales are not expected to eat more after food cue exposure than without. Further, the correlations between food exposure induced cue reactivity, actual food intake, and respectively the EMO and R subscale scores are expected to be low and non-significant.

\section{Method}

\section{Participants}

Female psychology first-years $(n=58)$ were recruited for this study. Their age ranged from 18 to 27 years $(\mathrm{M}=$ $20.2, \mathrm{SD}=2.1$ ) and their Body Mass Index $(\mathrm{BMI}=\mathrm{kg} /$ $\left.\mathrm{m}^{2}\right)$ ranged from 16.8 to $34.4(\mathrm{M}=22.3, \mathrm{SD}=2.99)$.

\section{Assessment}

Self-reported Eating Type. The Dutch Eating Behavior Questionnaire (DEBQ) ${ }^{10,11}$ was used to measure external, emotional, and restrained eating.

Self-reported subjective food cue reactivity (SSCR). During food cue exposure the participant was presented with 5 bowls with snack foods (milky ways, cake, chips, peanuts, and marshmallows). She smelled each of the 5 food items intensely (see procedure) and rated food liking and food wanting by indicating how much she liked the smell of the foods, how much she wanted the foods and how much the foods were mouth-watering, on 5-point scales ranging from 1 (not at all) to 5 (very much). Subjective cue reactivity (SSCR) was defined as the mean score on these items, with higher scores reflecting increasing subjective cue reactivity.

\section{Actual Food Intake}

Food intake was measured unobtrusively during a bogus taste test. Participants were presented with 5 preweighed large bowls brim-full with tasty high caloric snacks in small pieces: approximately 1100 grams of mini milky ways (449 kcal/100 g), 900 grams of cake (428 kcal/ $100 \mathrm{~g}$ ), 600 grams of potato chips (525 kcal/100 g), 1150 grams of peanuts $(630 \mathrm{kcal} / 100 \mathrm{~g})$ and 750 grams of marshmallows (340 kcal/100 g). After the 'taste test' the remaining food was re-weighed and kcal intake was calculated.

\section{Procedure}

Each participant was tested individually in two conditions; a food cue exposure condition and a control condition (within subject design, counterbalanced order, randomly assigned to a condition in the first session). Both sessions took place with a one-week gap at the same day of the week and at the same time of the day. The participant was instructed not to consume foods or drinks other than tea, coffee or water from 2 hrs before participation. After entering the lab, participants in the food cue exposure condition were exposed to the intense smells of snack foods during which they were prevented from eating. The participant was exposed to five types of tasty snacks (chocolate, nuts, cake, chips, and marshmallows). Each food item was taken to the nose and intensely smelled. The food cue exposure lasted for $10 \mathrm{~min}$ during which the experimenter led the participant through the exposure procedure following the method of Jansen. ${ }^{2,13,14}$ After 10 min of exposure, SSCR was rated. In the control condition, the participants performed an irrelevant computer task during ten minutes. Then the 15 min taste test (see assessment) started. The participant was instructed to taste all the foods and to complete a taste questionnaire. She was invited to help herself to any of the remaining foods after finishing the taste test. After the first session taste test was finished, the participant completed a compliance check considering refraining from food intake from $2 \mathrm{hrs}$ before participation. Following the taste test in the second session, the participant completed the DEBQ and the compliance check, whereupon her weight and height were determined and study credits were given. The bowls with food were weighed before and reweighed after each taste test. The local Ethical Committee approved the study and all participants provided written informed consent. 
TABLE 1. Mean kcal intake (Standard Deviation) for high and low scorers (median split) in the food exposure and control condition, followed by 2 (condition: exposure $\times$ control) $\times 2$ (group: high $\times$ low scorers) ANOVA's with food intake (kcal) as the dependent variable

\begin{tabular}{|c|c|c|c|c|c|c|c|}
\hline & \multicolumn{2}{|c|}{ High Scorers } & \multicolumn{2}{|c|}{ Low Scorers } & \multicolumn{3}{|c|}{ ANOVA } \\
\hline & $\begin{array}{l}\text { Exposure } \\
\text { M (SD) }\end{array}$ & $\begin{array}{l}\text { Control } \\
\mathrm{M}(\mathrm{SD})\end{array}$ & $\begin{array}{c}\text { Exposure } \\
M(S D)\end{array}$ & $\begin{array}{l}\text { Control } \\
\mathrm{M}(\mathrm{SD})\end{array}$ & $\begin{array}{c}\text { Condition } \\
F(1,56)\end{array}$ & $\begin{array}{l}\text { Group } \\
F(1,56)\end{array}$ & $\begin{array}{c}\text { Condition } \times \\
\text { Group } F(1,56)\end{array}$ \\
\hline DEBQ-EE & $436(157)$ & $388(170)$ & 377 (247) & 318 (184) & $6.8^{\mathrm{a}}$ & 1.97, ns & $<1$ \\
\hline DEBQ-EMO & 420 (197) & 368 (184) & 395 (217) & $340(175)$ & $6.75^{\mathrm{a}}$ & $<1$ & $<1$ \\
\hline DEBQ-R & 400 (206) & 364 (188) & 414 (208) & 347 (174) & $6.34^{\mathrm{a}}$ & $<1$ & $<1$ \\
\hline
\end{tabular}

Notes: DEBQ, Dutch Eating Behavior Questionnaire; EE, External Eating subscale; EMO, Emotional Eating subscale; R, Restraint subscale.

${ }^{\mathrm{a}} p<0.03$.

\section{Results}

\section{Food Intake}

Participants were divided into high $(n=30, M=$ $3.68, S D=0.37)$ and low $(n=28, M=2.72, S D=$ 0.38 ) scorers on the EE subscale (median-split; median $=3.3$ ). To test the hypothesis on predictive validity - high EE scorers eat more after food cue exposure than without, whereas low EE scorers do not show increased food intake after food cue exposure - a 2 (group: high vs low EE) x 2 (condition: cue exposure vs control) repeated measures ANOVA was done on food intake (amount of kcal eaten). The ANOVA showed no significant interaction effect and no main effect for group but a significant main effect for condition (see Table 1). Mean food intake was significantly larger after cue exposure $(M=408, S D=206)$ than without $(M=$ $354, S D=179), t(57)=2.6, p=0.01$. Further t-tests showed that the low external eaters ate significantly more after cue exposure than without, $t(27)=2.2$, $p=0.04$, whereas the high external eaters did not, $t(29)=1.6$, NS (see Table 1). This is precisely the opposite of what was predicted; the external eating theory states that specifically high external eaters will eat more after food cue exposure than without, but not the low external eaters.

\section{Predictive Validity}

Pearson P-M correlations showed significant associations between self-reported EE scores and SSCR $(r=0.35, p<0.01)$. There was however no significant correlation between EE scores and actual food intake after food cue exposure, $(r=0.1$, NS), and also no significant correlation between SSCR and actual food intake ( $r=0.19$, NS).

\section{Pure External Eaters}

Inspection of the external eating and emotional eating (EMO) subscales showed a high correlation between both, $r=0.47, p<0.03$, implying that many high scorers on the EE also score high on EMO. It might be argued that the predicted effects that were not found will only appear in a specific subsample that scores high on the EE and low on the EMO subscale. We therefore tested the hypothesis again in only this subgroup. Ten participants scored high on EE and low on EMO, and could be considered pure external eaters. The pure external eaters did however not eat more after food cue exposure $(M=400, S D=118)$ than without $(M=$ $358, S D=197), t(9)<1$. Also in this small but pure subsample, EE scores were unrelated to food intake, $r=-0.06$, and EE scores were also unrelated to SSCR, $r=0.17$. Furthermore, SSCR was unrelated to actual food intake after food cue exposure, $r=-0.09$, NS.

\section{Discriminant Validity}

Participants were successively divided into high and low scorers (median-split) on the DEBQ-EMO (median $=2.35$; high scorers $M=3.19, S D=0.52$; low scorers $M=1.84, S D=0.33$ ) and high and low scorers on the DEBQ-R (median $=2.9$; high scorers $M=3.59, S D=0.42$; low scorers $M=2.14, S D=$ 0.67). Table 1 shows the mean food intake for groups and conditions. For each scale (EMO and R) a 2 (Condition) x 2 (Group) ANOVA on kcal intake was done, see also Table 1. No significant interaction effects and no significant group effects emerged, in neither ANOVA, but significant effects for condition were found in both analyses: again, food intake was significantly higher after food cue exposure than without. Paired $t$-tests within the emotional eaters showed that both the low $(n=29)$ and the high $(n=29)$ emotional eaters tended to eat more after food cue exposure than without, low EMO: $t(28)=1.9, p=0.07$ and high EMO: $t(28)=$ $1.8, p=0.09$. Low R scorers $(n=32)$ did eat significantly more after food cue exposure than without $(t(31)=2.5, p=0.017)$ whereas high $\mathrm{R}$ scorers $(n=26)$ did not eat more after exposure than without $(t(25)=1.1, \mathrm{NS})$. 
We then tested correlations between subscale scores, SSCR and kcal intake. The pattern appeared to be roughly the same as for the EE subscale: EMO scores $(r=0.06)$ and R scores $(r=0.07)$ were unrelated to kcal intake. EMO scores correlated marginally significant with SSCR $(r=0.23, p=0.09), \mathrm{R}$ scores did not $(r=-0.16$, NS). SSCR did not correlate with actual food intake, not for EMO ( $r=0.19$, NS) and not for R ( $r=0.19$, NS).

To sum up, food intake is significantly larger after food cue exposure than without, but this effect is essentially unrelated to subjective self-reports and self-reported specific types of eaters.

\section{Discussion}

This study tested the construct validity of the DEBQ-EE subscale. Highly external eaters were supposed to show exaggerated reactivity to food cues and, consequently, increased food intake. ${ }^{10,11,12}$ In line with these expectations, selfreported EE scores correlated positively with selfreported subjective cue reactivity during food exposure. It was concluded that participants are quite consistent in their subjective self-reports on food responsiveness. But, contrary to prediction, selfreported cue reactivity was not at all related to actual food intake and also EE scores were unrelated to actual food intake. A first conclusion therefore is that self-reported external eating is no valid measure of actual external eating: highly external eaters, selected with the DEBQ external eating scale, do not eat more in response to external food cues than without these food cues. Interestingly, people that were identified as non-external eaters (low scorers on the external eating scale) actually did eat more in response to external food cues than without these food cues. This is exactly the opposite to what was predicted; external eating theory states that specifically high external eaters will eat more after food cue exposure than without, but not the low external eaters. The laboratory-eating task that was used might be considered sensitive and powerful enough to find differential behavioral responses because mean food intake was significantly larger in the cue exposure condition than in the control condition, and low external eaters actually did show the behavioral response that was expected to be characteristic for high external eaters. Also, the manipulation of external food cue exposure was successful in eliciting self-reported subjective cue reactivity in especially high external eaters. But external eating scores and food intake were not at all associated, even not when only the 'pure' external eaters were considered. Unlike what is predicted by the DEBQ, external eating scores on the DEBQ are not associated with actual food intake. In this study the DEBQ-external eating scale showed no predictive validity when it comes to actual eating behavior.

A second conclusion is that the selected eating subtypes (EE, EMO or R) did not behave very different from each other. The EMO and R subscale scores were not at all associated with food intake, in neither condition, as was the case for the EE subscale. Considering the identical eating behavior patterns of high and low scorers on the three specific subscales of the DEBQ, and the high inter-correlation between the EE and EMO subscales $(r=0.47)$, one might put forward that the DEBQ subscales lack any discriminative validity. The data therefore question whether it is necessary to distinguish these three different types of eaters. The scales clearly do not reflect independent mechanisms for overeating. High scorers on these scales typically are generally 'eating-concerned' instead of external, emotional or restraint, whereas low scorers are generally unconcerned. Common characteristics of high scorers on all subscales are their concerns about food intake and their more or less successful intentions to control their eating in response to all possible kinds of disinhibitors, like emotions, experienced diet-breaking, and palatable food cues. It might be a rewarding enterprise to develop a very short scale that simply identifies the concerned eater without any theoretical pretensions.

\section{References}

1. Bulik CM, Sullivan PF, Carter FA, McIntosh V, Joyce PR. The role of exposure with response prevention in the cognitive-behavioural therapy for bulimia nervosa. Psych Med 1998;28:611623

2. Jansen A. A Learning model of binge eating: cue reactivity and cue exposure. Behav Res Ther 1998;36:257-272.

3. Jansen A, Theunissen N, Slechten K, Nederkoorn C, Mulkens S, Roefs A. Overweight children overeat after exposure to food cues. Eating Beh 2003;4:197-209.

4. Nederkoorn C, Smulders FTY, Jansen A. Cephalic phase responses, craving and food intake in normal subjects. Appetite 2000;35:4555.

5. Nederkoorn C, Smulders FTY, Havermans R, Jansen A. Exposure to binge food in bulimia nervosa: finger pulse amplitude as a potential measure of urge to eat and predictor of food intake. Appetite 2004;42:125-130.

6. Guerrieri R, Nederkoorn C, Jansen A. How impulsiveness and variety influence food intake in a sample of healthy women. Appetite 2007;45:119-122.

7. Guerrieri R, Nederkoorn C.Jansen A. The interaction between impulsivity and a varied food environment: its influence on food intake and overweight. Int J Obes 2008;32:708-714. 
8. Jansen A, Klaver J, Merckelbach H, Van den Hout M. Restrained eaters are rapidly habituating sensation seekers. Behav Res Ther 1989;27:247-252.

9. Schachter S, Rodin J. Obese humans and rats. Washington, DC: Erlbaum/Halsted 1974.

10. Van Strien T, Frijters JE, Bergers GPA, Defares PB. The Dutch Eating Behaviour Questionnaire (DEBQ) for assessment of restrained, emotional and external eating behaviour. Int J Eat Disord 1986;5:295-315.

11. Van Strien T. Nederlandse vragenlijst voor eetgedrag [Dutch Eating Behaviour Questionnaire, manual]. Amsterdam, Boom Test Publishers 2005.
12. Van Strien T. Emotioneel en extern eten. Het verschil en de therapie [Emotional and external eating. The difference and the therapy]. De Psycholoog 41:193-198, 2006.

13. Jansen A, Broekmate J, Heymans M. Cue exposure vs self-control in the treatment of binge eating: a pilot study. Behav Res Ther 1992;30:235-241.

14. Jansen A, Van den Hout M, Van Loof C, Zandbergen J, Griez E. A case of bulimia successfully treated with cue exposure. Behav Ther Exp Psych 1989;20:327-332.

15. Burton P, Smit HJ, Lightowler HJ. The influence of restrained and external eating patterns on overeating. Appetite. 2007;49: 191-197. 